Supplement of Biogeosciences, 13, 1329-1339, 2016

http://www.biogeosciences.net/13/1329/2016/

doi:10.5194/bg-13-1329-2016-supplement

(C) Author(s) 2016. CC Attribution 3.0 License.

(c) (i)

Supplement of

\title{
Evaluation of wetland methane emissions across North America using atmospheric data and inverse modeling
}

Scot M. Miller et al.

Correspondence to: Scot M. Miller (scot.m.miller@gmail.com)

The copyright of individual parts of the supplement might differ from the CC-BY 3.0 licence. 
This supplement provides more detail on the atmospheric observations, the wetland methane $\left(\mathrm{CH}_{4}\right)$ flux estimates, and the statistical methods used throughout the paper.

\section{S1 Atmospheric observation sites}

Here we describe, in greater depth, the atmospheric $\mathrm{CH}_{4}$ observations collected across the US 5 and Canada in 2007-2008. The observations used here are the same as those in Miller et al. (2013) and Miller et al. (2014b), and the discussion below summarizes the data descriptions in those papers.

The $\mathrm{CH}_{4}$ analysis in the main article uses either real or synthetic data at US and Canadian observation sites - a total of 14703 observations. Of those measurements, 2009 are from observation towers in Canada. These towers (from east to west) include Chibougamau, Quebec $\left(\mathrm{CHM}, 50^{\circ} \mathrm{N}, 74^{\circ} \mathrm{W}, 30 \mathrm{~m}\right.$ above ground level); Fraserdale, Ontario (FSD, 50 ${ }^{\circ} \mathrm{N}, 83^{\circ} \mathrm{W}, 40 \mathrm{~m}$ agl); East Trout Lake, Saskatchewan (ETL, $54^{\circ} \mathrm{N}, 104^{\circ} \mathrm{W}, 105 \mathrm{~m}$ agl); and Candle Lake, Saskatchewan (CDL, 54 ${ }^{\circ} \mathrm{N}, 105^{\circ} \mathrm{W}, 30 \mathrm{~m}$ agl, 2007 only). These sites, operated by Environment Canada, measure $\mathrm{CH}_{4}$ continuously. In this study, as in Miller et al. (2014b), we use only afternoon averages of the $\mathrm{CH}_{4}$ data and WRF-STILT model output (1pm - 7pm local time); small scale heterogeneities in the continuous data caused by turbulent eddies and incomplete mixing make it difficult to model finer scale temporal patterns in the data. The 2009 observations at these Canadian sites represent the total after averaging.

An additional $4984 \mathrm{CH}_{4}$ observations were collected from US towers operated by the National Oceanic and Atmospheric Administration (NOAA) and its partners. These observations include daily flask samples from a number of tower sites (weekly at Argyle and Ponca City): Argyle, Maine (AMT, $45^{\circ} \mathrm{N}, 69^{\circ} \mathrm{W}, 107 \mathrm{~m}$ above ground level (agl)); Erie, Colorado (BAO, 40 ${ }^{\circ} \mathrm{N}, 105^{\circ} \mathrm{W}, 300 \mathrm{~m}$ agl); Park Falls, Wisconsin (LEF, 46 ${ }^{\circ} \mathrm{N}, 90^{\circ} \mathrm{W}, 244 \mathrm{~m}$ agl), Martha's Vineyard, Massachusetts (MVY, $41^{\circ} \mathrm{N}, 71^{\circ} \mathrm{W}, 12 \mathrm{~m}$ agl); Niwot Ridge and Niwot Forest, Colorado (NWF, $\mathrm{NWR}, 40^{\circ} \mathrm{N}, 105^{\circ} \mathrm{W}, 2,3,23 \mathrm{~m}$ agl); Ponca City, Oklahoma (SGP, $37^{\circ} \mathrm{N}, 97^{\circ} \mathrm{W}, 60 \mathrm{~m}$ agl); West Branch, Iowa (WBI, $42^{\circ} \mathrm{N}, 93^{\circ} \mathrm{W}, 379 \mathrm{~m}$ agl); Walnut Grove, California (WGC, $38^{\circ} \mathrm{N}, 121^{\circ} \mathrm{W}$, $91 \mathrm{~m}$ agl), and Moody, Texas (WKT, $31^{\circ} \mathrm{N}, 97^{\circ} \mathrm{W}, 122,457 \mathrm{~m}$ agl).

A further $7710 \mathrm{CH}_{4}$ measurements were obtained from flask samples on regular NOAA aircraft flights and from the START08 (Stratosphere-Troposphere Analyses of Regional Transport 2008) measurement campaign (Pan et al., 2010). As in Miller et al. (2013), we only use aircraft observations up to $2500 \mathrm{~m}$ above ground level. Observations at higher altitudes are less sensitive to surface emissions and were instead used by Miller et al. (2013) to optimize the estimated $\mathrm{CH}_{4}$ boundary condition or background concentrations. In this study, we only use aircraft and tower-based observations collected during daytime hours.

We further screen the data for biomass burning influence at the Canadian sites and at Park Falls, Wisconsin. At these sites, we remove all days with CO that peaks above $200 \mathrm{ppb}$, as was done in Miller et al. (2014b). When these sites see influence from distant anthropogenic emissions, CO is often elevated, but it rarely exceeds $200 \mathrm{ppb}$ except during time periods with known fires (Miller et al., 2008).

\section{S2 WETCHIMP $\mathrm{CH}_{4}$ flux models}

This section of the supplement details the WETCHIMP $\mathrm{CH}_{4}$ estimates from Melton et al. (2013) and Wania et al. (2013). The seven $\mathrm{CH}_{4}$ estimates used in this study are shown in Fig. S1. The wetland $\mathrm{CH}_{4}$ fluxes estimated by these models varies widely - both in magnitude and in spatial distribution. For example, the SDGVM model places large fluxes over the US Corn

Belt relative to other regions while other models like Orchidee place large fluxes in Northern 
Canada that extent far into the Northwest Territories. For a more in-depth inter-comparison of these flux estimates, refer to Melton et al. (2013) and Wania et al. (2013).

\section{S3 Additional information on the model selection setup}

In the main article, we use synthetic $\mathrm{CH}_{4}$ data and a model selection framework to examine

whether atmospheric observations can detect aggregate wetland $\mathrm{CH}_{4}$ fluxes (Sect. 2.2 and 3).

This section first describes the synthetic data experiments (Sect. 2.2) followed by additional detail on the model selection runs that use real data (Sect. 2.3). The methods described here are adapted from Fang et al. (2014), Shiga et al. (2014), and Fang and Michalak (2015), and the discussion below parallels the descriptions in those studies.

The synthetic observations include contributions from anthropogenic sources, from wetlands, and from simulated model and measurement errors:

$$
z_{\text {synthetic }}=\mathbf{H}\left(s_{\text {anthro }}+s_{\text {wetland }}\right)+\boldsymbol{\epsilon}
$$

In this equation, $\boldsymbol{z}_{\text {synthetic }}(n \times 1)$ represents the synthetic observations generated for an observation site. The vector $\boldsymbol{s}_{\text {anthro }}(m \times 1)$ represents emissions from anthropogenic sources, and $\boldsymbol{s}_{\text {wetland }}(m \times 1)$ represents wetland fluxes. The footprint or sensitivity matrix $\mathbf{H}(n \times m)$, generated from WRF-STILT, models the impact of these emissions at the observation sites.

In this study, we use the a priori anthropogenic emissions estimates from Miller et al. (2013) and Miller et al. (2014b) for $\boldsymbol{s}_{\text {anthro }}$. Those studies used activity data from the EDGAR inventory and a model selection framework to construct a prior anthropogenic emissions estimate. These EDGAR activity datasets include economic or demographic data that may predict the spatial distribution of $\mathrm{CH}_{4}$ emissions (e.g., human or ruminant population maps).

The wetland fluxes $\left(\boldsymbol{s}_{\text {wetland }}\right)$ in Eq. S1 are taken from the WETCHIMP $\mathrm{CH}_{4}$ flux models (experiment two in Melton et al. (2013)). For the synthetic data experiments, we scale these models to match the Hudson Bay Lowlands (HBL) budget estimated by Pickett-Heaps et al. (2011), Miller et al. (2014b), and Wecht et al. (2014). This scaling ensures more consistent or 70 representative results. The larger the wetland flux, the more likely that the observation network can detect a $\mathrm{CH}_{4}$ fluxes from wetlands. Therefore, if we conduct the synthetic data experiment using a flux model that has an anomalously large magnitude, we would concomitantly obtain anomalously optimistic results.

As in Miller et al. (2013) and Miller et al. (2014b), the emissions ( $\boldsymbol{s}_{\text {anthro }}$ and $\left.\boldsymbol{s}_{\text {wetland }}\right)$ are regridded to a spatial resolution of $1^{\circ}$ latitude by $1^{\circ}$ longitude. The EDGAR activity data do not have any seasonality, so the anthropogenic emissions $\left(\boldsymbol{s}_{\text {anthro }}\right)$ are seasonally invariant. The WETCHIMP models have a monthly temporal resolution, as in Melton et al. (2013). That study provides flux estimates for the years 1993-2004; we use the mean of these ten years for all analysis in this study.

The final term in equation S1, $\epsilon(n \times 1)$, represents simulated errors in the measurements, in WRF-STILT, and in the fluxes ( $\boldsymbol{s}_{\text {anthro }}$ and $\left.\boldsymbol{s}_{\text {wetland }}\right)$. The errors in $\boldsymbol{\epsilon}$ are distributed according to the covariance matrix $\boldsymbol{\Psi}(n \times n)$ (Eq. 1):

$$
\begin{aligned}
\boldsymbol{\epsilon} & \sim \mathcal{N}(\mathbf{0}, \boldsymbol{\Psi}) \\
\boldsymbol{\Psi} & =\mathbf{H Q} \mathbf{H}^{T}+\mathbf{R}
\end{aligned}
$$

The variances and covariances within $\Psi$ fall into two different categories. The first category are errors due to imperfect emissions, described by covariance matrix $\mathbf{Q}(m \times m)$. In atmospheric inversion studies, this matrix is typically termed the a priori covariance matrix. The diagonal elements of $\mathbf{Q}$ describe a set of variances - differences between the prior fluxes and the unknown true emissions over long spatial or temporal scales. The off-diagonal elements of $\mathbf{Q}$ describe any 


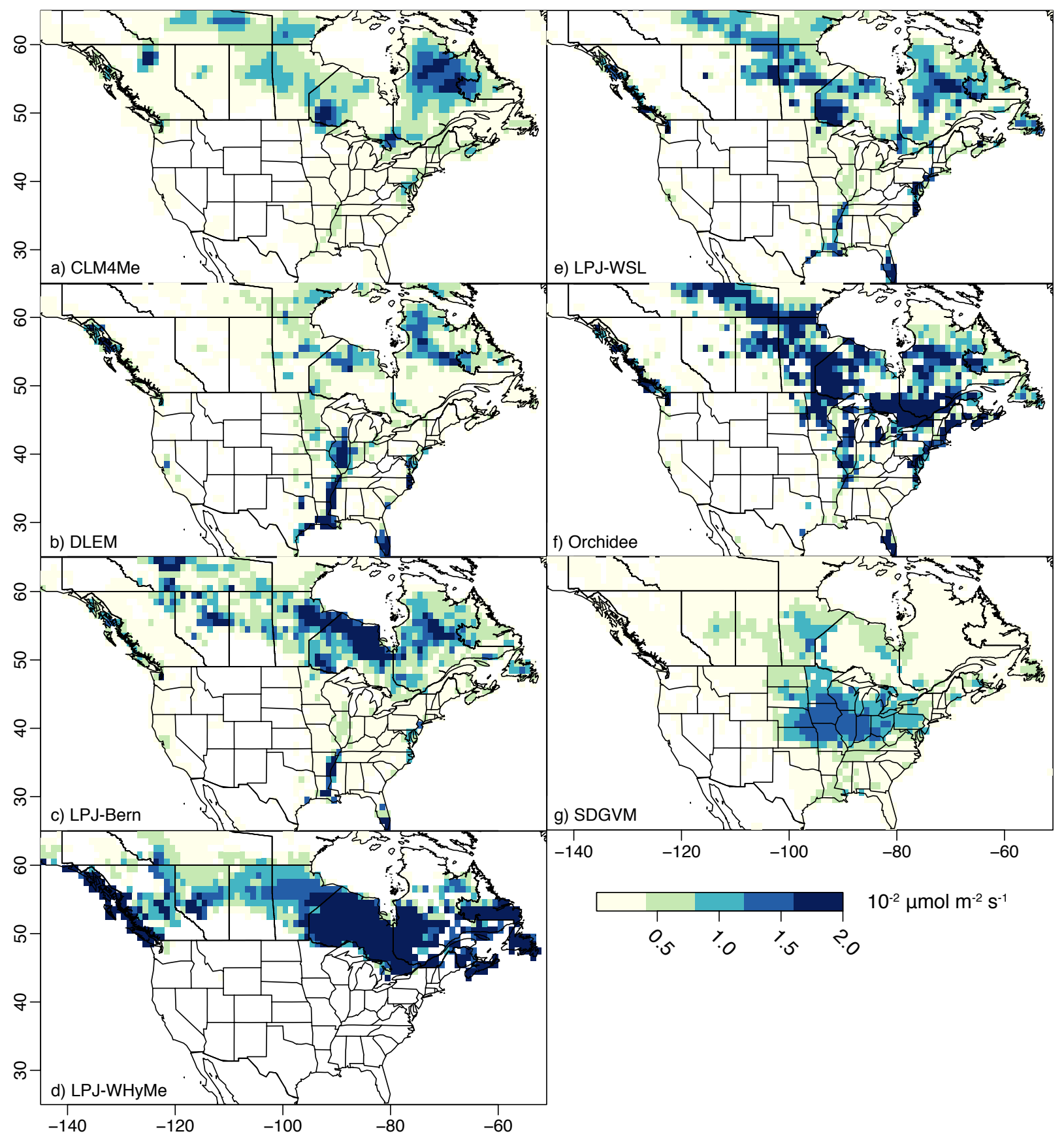

Figure S1: Annual mean wetland $\mathrm{CH}_{4}$ fluxes from seven different WETCHIMP estimates (Melton et al., 2013; Wania et al., 2013). The fluxes shown here are averaged over the 1993-2004 study period. Note that the fluxes shown above are averaged over the entire grid cell, not per $\mathrm{m}^{2}$ of wetlands. 
spatial and/or temporal covariances in these differences. In Eq. S3, the footprint or sensitivity matrix $(\mathbf{H})$ projects $\mathbf{Q}$ from units of (flux $)^{2}$ into units of parts per billion squared, $(\mathrm{ppb})^{2}$.

We refer to the second type of errors as model-data mismatch errors, denoted by covariance matrix $\mathbf{R}(n \times n)$. These include all errors in the WRF-STILT model or the measurements that are unrelated to an imperfect flux estimate. Examples of model-data mismatch errors include measurement error, atmospheric transport error, or errors due to the spatial or temporal resolution of WRF-STILT.

The synthetic data simulations in this study use values of $\mathbf{Q}$ and $\mathbf{R}$ estimated in Miller et al. (2013) and Miller et al. (2014b). In the synthetic data studies, we construct a statistical model that is representative of a prototypical real data inverse model. Similarly, we want to use values for $\mathbf{Q}$ and $\mathbf{R}$ that are representative of what one would likely encounter in a real-data setup. Miller et al. (2013) and Miller et al. (2014b) constructed real data inverse models over the US and Canada, respectively, using the same atmospheric observations and WRF-STILT simulations used in this study. Those studies used a model selection framework to find prior models that show optimal fit against available observations. In each study, the authors then estimated the elements of $\mathbf{Q}$ and $\mathbf{R}$ using that prior model. The resulting estimates of $\mathbf{Q}$ are representative of prior models that shows optimal agreement with atmospheric observations. For case study (b) (no anthropogenic emissions), we estimate $\mathbf{Q}$ using the same approach as in Shiga et al. (2014). In that study, the authors used the estimated variances and covariances of the remaining fluxes (in this case wetland fluxes) to populate $\mathbf{Q}$.

In the real data experiments (Sect. 2.3), we estimate unique values of $\mathbf{Q}$ and $\mathbf{R}$ each time we run the model selection framework. We estimate these parameters using Restricted Maximum Likelihood (RML) (Corbeil and Searle, 1976; Kitanidis, 1995; Michalak et al., 2004; Gourdji et al., 2012), the same procedure used in Miller et al. (2013) and Miller et al. (2014b).

We use these covariance matrices to compute $\boldsymbol{\epsilon}$ through several steps. First, we compute the Cholesky decomposition of the combined covariance matrix $\Psi$ :

$$
\Psi=\mathbf{C C}^{T}
$$

The covariance matrix $\boldsymbol{\Psi}$ has units of $(\mathrm{ppb})^{2}$, but its Cholesky decomposition (C) has units of ppb. With this decomposition in hand, we next simulate a set of errors, $\epsilon$ (e.g., Fang et al., 2014; Shiga et al., 2014):

$$
\begin{aligned}
\boldsymbol{\epsilon} & =\mathbf{C u} \\
\boldsymbol{u} & \sim \mathcal{N}(\mathbf{0}, \mathbf{1})
\end{aligned}
$$

where $\boldsymbol{u}$ represents a set of randomly-generated numbers with a mean of zero and variance of one.

We simulate 1000 synthetic datasets for each experiment to adequately sample the random errors in $\boldsymbol{\epsilon}$. We then use the model selection framework to find the optimal candidate model for each of these datasets. The results presented in Fig. 3 are therefore the composite of thousands of model selection runs: one model selection run for each synthetic dataset. We also estimate the coefficients $(\boldsymbol{\beta})$ in Eq. 1 using Lagrange multipliers to ensure that none of the estimated coefficients have unrealistic negative values (e.g., Miller et al., 2014a).

In the real data setup (Sect. 2.3), we run the model selection procedure once for each of the seven WETCHIMP flux estimates. We only include one of the seven WETCHIMP flux models in each model selection run. As a result, the WETCHIMP models do not compete against one another for selection. In each run, the model selection framework can select the given WETCHIMP model in any of the four geographic regions and any of the four seasons. 

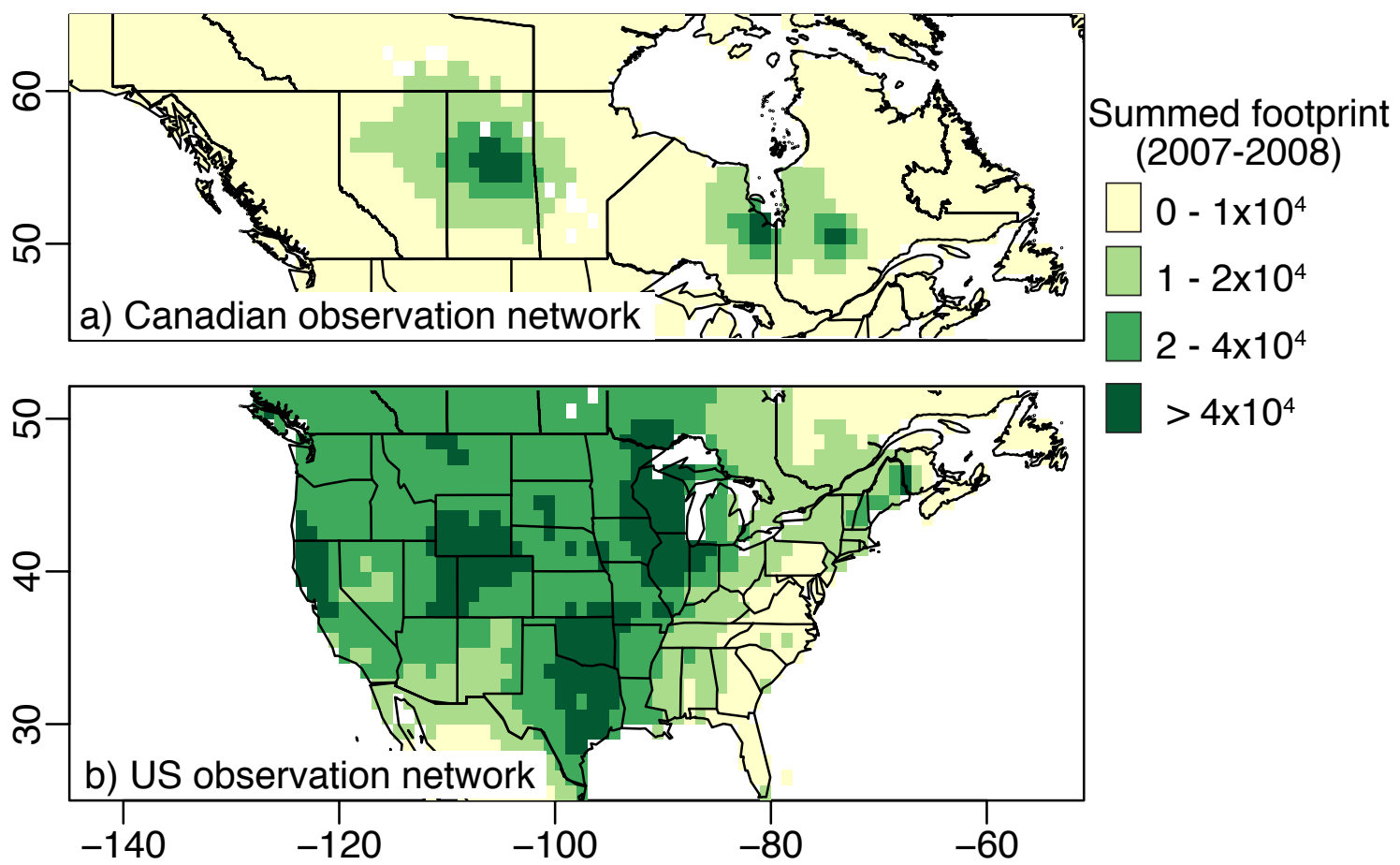

$>4 \times 10^{4}$

Figure S2: Total, summed footprint from the (a) Canadian and (b) US observation networks. The observation sites incorporated into this figure are shown in Fig. 2. Each individual footprint (associated with an individual atmospheric observation) has units of concentration per unit flux (ppb per $\mu \mathrm{mol} \mathrm{m}{ }^{-2} \mathrm{~s}^{-1}$ ). In this figure, we sum all footprints for 2007-2008.

\section{$\mathrm{S} 4$ Overall sensitivity of the observation network to $\mathrm{CH}_{4}$ fluxes}

In this section, we describe the overall footprint or sensitivity of the observation network to $\mathrm{CH}_{4}$ fluxes. This sensitivity will play at least some role in network's ability to detect wetland $\mathrm{CH}_{4}$ fluxes. The WRF-STILT model quantifies this sensitivity in terms of a footprint. Each row the matrix $\mathbf{H}$ is the footprint associated with a different atmospheric $\mathrm{CH}_{4}$ observation. In Fig. S2, we plot these footprints, summed over all of 2007-2008.

This figure show several distinctive patterns. First, the US network has a higher sensitivity than the Canadian network. This pattern is due to the larger number of observation sites over the US. Second, the highest sensitivities are clustered in distinctive regions with multiple observation sites - Wisconsin, Texas/Oklahoma, and California, among other regions.

\section{S5 Soil freeze/thaw estimates from NARR}

Figure S3 shows the soil freeze/thaw cycle at different depths averaged across the HBL. These estimates are taken from North American Regional Reanalysis (NARR) (Mesinger et al., 2006), and the values shown in Fig. S3 are average values for each month. The main article references this figure in a discussion of the $\mathrm{CH}_{4}$ flux seasonal cycle (Sect. 4.3).

\section{S6 Additional model-data time series}

This section includes additional model-data time series analogous to those in Fig. 4. That figure compares averaged concentrations modeled by WRF-STILT against monthly-averaged observations at four different observation sites. The sites displayed in that figure are located 


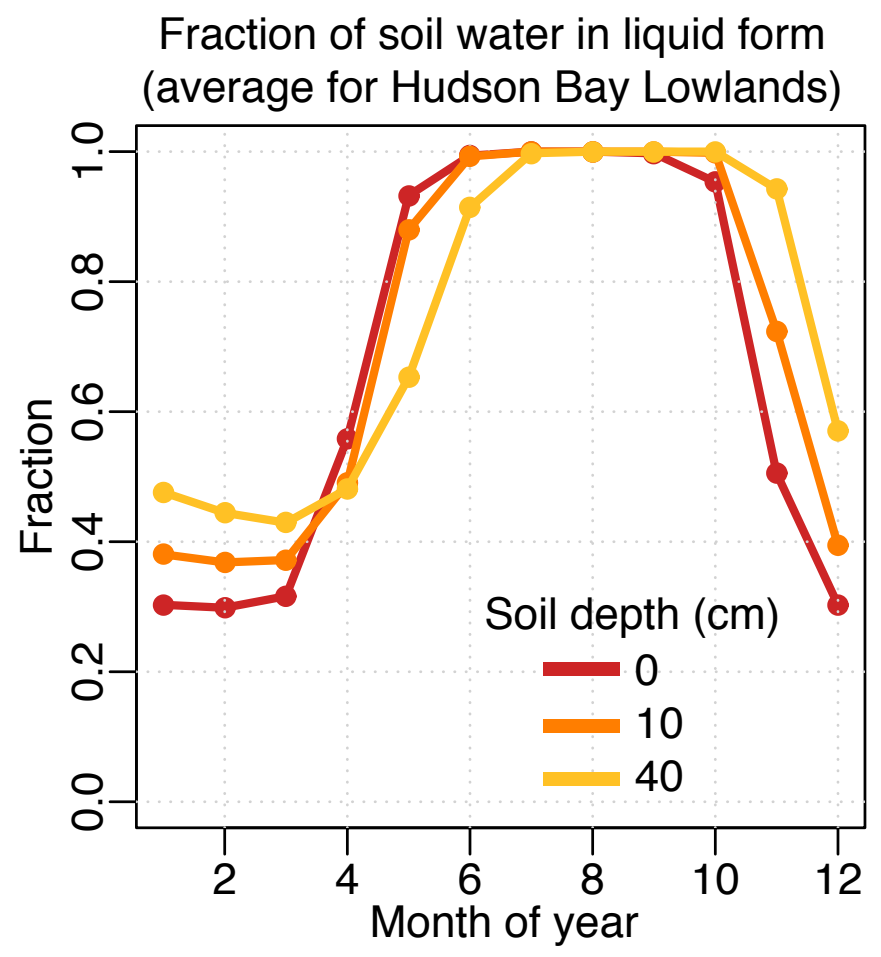

Figure S3: This figure displays the fraction of soil water that is unfrozen for the HBL in different seasons and at different soil depths. Estimates are taken from NARR (Mesinger et al., 2006).

near large wetlands and in regions where the synthetic data experiments had a high success rate (Fig. 3). The sites displayed in Fig. S4 in this section are located further from wetlands and in regions that had a low success rate in the BIC experiments. At many of the sites in Fig. S4, the modeled wetland signal is difficult to distinguish. These sites contrast with those in Fig. 4 which "see" a relatively large $\mathrm{CH}_{4}$ increment from wetlands.

\section{S7 Validation of the WRF-STILT model}

This section describes work that validates the atmospheric transport estimated by WRF-STILT.

The supplements to Miller et al. (2013) and Miller et al. (2014b) provide detailed validation of the atmospheric transport and boundary condition estimate; refer to those papers for additional information. Those papers use the same WRF-STILT simulations and boundary condition estimate as in the present paper. This section of the Supplement discusses a number of key points or highlights.

A number of figures in Miller et al. (2013) and Miller et al. (2014b) illustrate the ability of the WRF-STILT model to reproduce daily and seasonal patterns in the observations at different sites across the US and Canada. Those studies used a geostatistical inverse model to estimate $\mathrm{CH}_{4}$ fluxes for the US and Canada, respectively. Figures S6 and S7 in Miller et al. (2013) compare modeled concentrations using this estimate against observed concentrations. The figures also display the estimated boundary condition and modeled concentrations with the EDGAR inventory for comparison. Modeled concentrations using the flux estimate in that paper can reproduce day-to-day variations in $\mathrm{CH}_{4}$ concentrations at tall tower sites in Wisconsin, California, and Texas (Fig. S6 in Miller et al. (2013)), among other tall tower locations. Figure 4 in Miller et al. (2014b) further compares modeled concentrations against observed concentrations at sites in Canada. WRF-STILT is able to reproduce seasonal variability in 


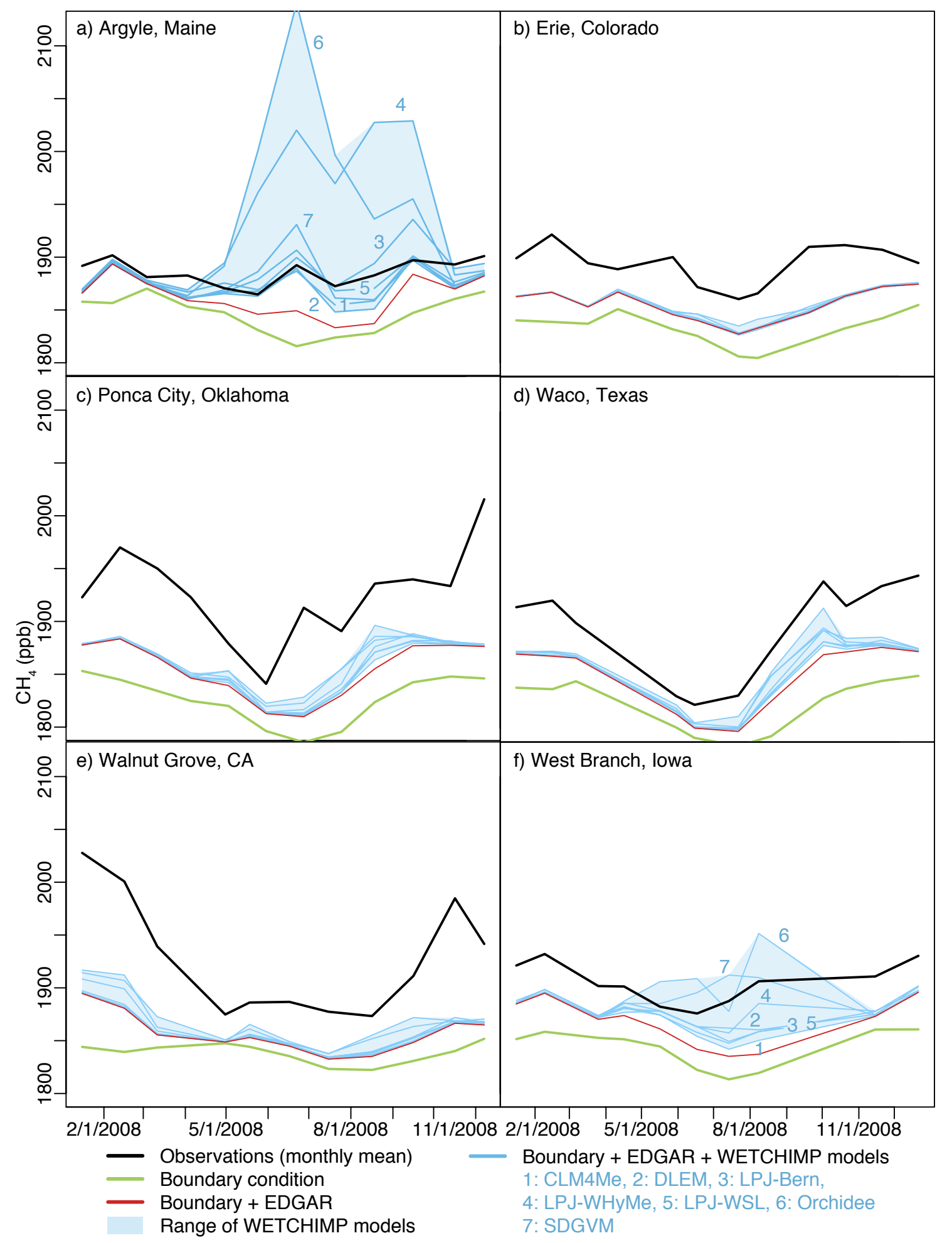

Figure S4: This figure is analogous to Fig. 4 and displays monthly-averaged model-data time series for additional atmospheric observation sites. 
$\mathrm{CH}_{4}$ concentrations at tower sites across Canada using the flux estimate from that study.

Miller et al. (2013) validate WRF-STILT's ability to reproduce the vertical structure of the atmosphere. Figure 4 in Miller et al. (2013) shows modeled and observed concentrations at regular NOAA aircraft sites, averaged across the 2007-2008 study period. The first panel of that figure displays observed and modeled concentrations averaged across all aircraft sites and the remaining panels display individual aircraft sites in Oklahoma, New Jersey, and Iowa. At all of these sites, WRF-STILT is able to reproduce $\mathrm{CH}_{4}$ enhancements near the surface and can reproduce vertical patterns in the aircraft observations.

The next section provides additional discussion of uncertainties and errors in the WRFSTILT model.

\section{S8 Uncertainty in the model-data framework}

A number of modeling and measurement uncertainties influence the results presented in this paper. These uncertainties are discussed in detail by Miller et al. (2013), Miller et al. (2014b), and Miller et al. (2014a). This section provides a summary of those discussions.

The model selection framework in this study accounts for modeling or measurement errors in the $\mathbf{R}$ covariance matrix (Eq. S3). This covariance matrix is typically included in a Bayesian synthesis or geostatistical inverse model (e.g., Michalak et al., 2004). The errors described by $\mathbf{R}$ are collectively referred to as model-data mismatch - any errors in the model-data framework that are unrelated to an imperfect flux estimate. This mismatch includes errors in the modeled winds, errors in the $\mathrm{CH}_{4}$ boundary condition, and any errors due to the finite spatial or temporal resolution of the model, among other possible error sources. This section of the supplement first discusses the overall magnitude of these model-data mismatch errors and then discusses individual components of the model-data mismatch, including potential errors in the estimated winds and in the boundary condition.

Both Miller et al. (2013) and Miller et al. (2014b) estimate the magnitude of model-data mismatch errors for observation sites in the US and Canada, respectively. These studies used a procedure known as Restricted Maximum Likelihood (RML) to estimate the parameters that define both the $\mathbf{R}$ and $\mathbf{Q}$ covariance matrices (e.g., Corbeil and Searle, 1976; Kitanidis, 1995; Michalak et al., 2004; Gourdji et al., 2012). The estimated mismatch errors range in magnitude from 12-13 ppb (standard deviations) at Canadian tower sites to 20-30 ppb at tower sites near oil and gas operations in the southern US (refer to Fig. S2 in Miller et al. (2013) and Fig. S6 in Miller et al. (2014b)). This magnitude (12-30 ppb) is equivalent to $25-70 \%$ of the average $\mathrm{CH}_{4}$ signal from North American emissions as seen at the various observation sites.

These model-data mismatch errors encompass numerous sources of error, but these errors are likely dominated by uncertainties in atmospheric transport. Nehrkorn et al. (2010) generated WRF meteorology for use in STILT and compared the estimated winds against US and Canadian radiosondes. They computed a root mean squared error (RMSE) of $2.5-4 \mathrm{~m} \mathrm{~s}^{-1}$ in the horizontal winds and found no change in error statistics at the top of the boundary layer. Hegarty et al. (2013) further coupled the STILT model with several weather models and found that simulations with WRF produced lower error statistics relative to other weather models.

Several existing studies have shown consistent results between WRF-STILT and other atmospheric models; this consistency may indicate a lack of large-scale bias in atmospheric transport estimated by WRF-STILT. For example, constraints on summertime US carbon monoxide emissions estimated with STILT and the GEOS-Chem model match to within 10\% (Miller et al., 2008; Hudman et al., 2008). $\mathrm{CH}_{4}$ budgets estimated for the HBL in Canada using WRF-STILT and GEOS-Chem are similar to within 10\% (Pickett-Heaps et al., 2011; Miller et al., 2014b; Wecht et al., 2014). Furthermore, $\mathrm{CH}_{4}$ budgets estimated for the US with WRF-STILT and GEOS-Chem match to within 10\% (Miller et al., 2013; Turner et al., 2015). 
The $\mathrm{CH}_{4}$ boundary condition or background concentrations are another, potentially large source of uncertainty in the $\mathrm{CH}_{4}$ modeling framework. To create this boundary condition, we interpolate atmospheric $\mathrm{CH}_{4}$ observations near or over the Pacific and Arctic Oceans to create a boundary "curtain." This curtain estimates $\mathrm{CH}_{4}$ concentrations over the Pacific and Arctic; it varies by latitude, altitude, and time (see Fig. S4 in Miller et al. (2014b)). We then sample concentrations along this curtain depending upon the ending latitude, altitude, and time of each WRF-STILT trajectory. These sampled concentrations become the boundary condition - an estimate of the $\mathrm{CH}_{4}$ concentration in air before that air reaches North America. Miller et al. (2013) and Miller et al. (2014b) describe this setup in greater detail along with the associated uncertainties. For example, Miller et al. (2013) compared the boundary condition estimate against aircraft data collected above $3000 \mathrm{~m}$ over the United States. They found an average difference of $2.7 \mathrm{ppb}$ between the aircraft observations and boundary condition estimate. Miller et al. (2013) then adjusted the boundary condition based upon this aircraft data. They subsequently estimated a total US $\mathrm{CH}_{4}$ budget using boundary conditions with and without the aircraft adjustment. The total $\mathrm{CH}_{4}$ budget using the aircraft-corrected boundary condition was approximately 5\% higher than the unadjusted boundary condition estimate. This result

indicates the possible effects of boundary condition uncertainties on a national-scale $\mathrm{CH}_{4}$ budget estimate.

\section{References}

Corbeil, R. R. and Searle, S. R.: Restricted maximum likelihood (REML) estimation of variance components in the mixed model, Technometrics, 18, pp. 31-38, 1976.

Fang, Y. and Michalak, A. M.: Atmospheric observations inform $\mathrm{CO}_{2}$ flux responses to enviroclimatic drivers, Global Biogeochem. Cy., p. 2014GB005034, doi:10.1002/2014GB005034, 2015 .

Fang, Y., Michalak, A. M., Shiga, Y. P., and Yadav, V.: Using atmospheric observations to evaluate the spatiotemporal variability of $\mathrm{CO}_{2}$ fluxes simulated by terrestrial biospheric models, Biogeosciences, 11, 6985-6997, doi:10.5194/bg-11-6985-2014, 2014.

Gourdji, S. M., Mueller, K. L., Yadav, V., Huntzinger, D. N., Andrews, A. E., Trudeau, M., Petron, G., Nehrkorn, T., Eluszkiewicz, J., Henderson, J., Wen, D., Lin, J., Fischer, M., Sweeney, C., and Michalak, A. M.: North American $\mathrm{CO}_{2}$ exchange: inter-comparison of modeled estimates with results from a fine-scale atmospheric inversion, Biogeosciences, 9, 457-475, doi:10.5194/bg-9-457-2012, 2012.

Hegarty, J., Draxler, R. R., Stein, A. F., Brioude, J., Mountain, M., Eluszkiewicz, J., Nehrkorn, T., Ngan, F., and Andrews, A.: Evaluation of Lagrangian particle dispersion models with measurements from controlled tracer releases, J. Appl. Meteorol. Clim., 52, 2623-2637, 2013.

Hudman, R. C., Murray, L. T., Jacob, D. J., Millet, D. B., Turquety, S., Wu, S., Blake, D. R., Goldstein, A. H., Holloway, J., and Sachse, G. W.: Biogenic versus anthropogenic sources of CO in the United States, Geophys. Res. Lett., 35, doi:10.1029/2007GL032393, 104801, 2008.

Kitanidis, P.: Quasi-linear geostatistical theory for inversing, Water Resour. Res., 31, 24112419, doi:10.1029/95WR01945, 1995.

Melton, J. R., Wania, R., Hodson, E. L., Poulter, B., Ringeval, B., Spahni, R., Bohn, T., Avis, C. A., Beerling, D. J., Chen, G., Eliseev, A. V., Denisov, S. N., Hopcroft, P. O., Lettenmaier, D. P., Riley, W. J., Singarayer, J. S., Subin, Z. M., Tian, H., Zürcher, S., Brovkin, V., van Bodegom, P. M., Kleinen, T., Yu, Z. C., and Kaplan, J. O.: Present state of global wetland 
extent and wetland methane modelling: conclusions from a model inter-comparison project (WETCHIMP), Biogeosciences, 10, 753-788, doi:10.5194/bg-10-753-2013, 2013.

Mesinger, F., Dimego, G., Kalnay, E., Mitchell, K., Shafran, P. C., Ebisuzaki, W., Jovi, D., Woollen, J., Rogers, E., Berbery, E. H., Ek, M. B., Fan, Y., Grumbine, R., Higgins, W., Li, H., Lin, Y., Manikin, G., Parrish, D., and Shi, W.: North American Regional Reanalysis, B. Am. Meteorol. Soc., 87, 343-360, doi:10.1175/BAMS-87-3-343, 2006.

Michalak, A., Bruhwiler, L., and Tans, P.: A geostatistical approach to surface flux estimation of atmospheric trace gases, J. Geophys. Res.-Atmos., 109, doi:10.1029/2003JD004422, 2004.

Miller, S. M., Matross, D. M., Andrews, A. E., Millet, D. B., Longo, M., Gottlieb, E. W., Hirsch, A. I., Gerbig, C., Lin, J. C., Daube, B. C., Hudman, R. C., Dias, P. L. S., Chow, V. Y., and Wofsy, S. C.: Sources of carbon monoxide and formaldehyde in North America determined from high-resolution atmospheric data, Atmos. Chem. Phys., 8, 7673-7696, doi: 10.5194/acp-8-7673-2008, 2008.

Miller, S. M., Wofsy, S. C., Michalak, A. M., Kort, E. A., Andrews, A. E., Biraud, S. C., Dlugokencky, E. J., Eluszkiewicz, J., Fischer, M. L., Janssens-Maenhout, G., Miller, B. R., Miller, J. B., Montzka, S. A., Nehrkorn, T., and Sweeney, C.: Anthropogenic emissions of methane in the United States, P. Natl. Acad. Sci. USA, 110, 20 018-20 022, doi:10.1073/pnas. 1314392110, 2013.

Miller, S. M., Michalak, A. M., and Levi, P. J.: Atmospheric inverse modeling with known physical bounds: an example from trace gas emissions, Geoscientific Model Development, 7, 303-315, doi:10.5194/gmd-7-303-2014, 2014a.

Miller, S. M., Worthy, D. E. J., Michalak, A. M., Wofsy, S. C., Kort, E. A., Havice, T. C., Andrews, A. E., Dlugokencky, E. J., Kaplan, J. O., Levi, P. J., Tian, H., and Zhang, B.: Observational constraints on the distribution, seasonality, and environmental predictors of North American boreal methane emissions, Global Biogeochem. Cy., 28, 146-160, doi:10. 1002/2013GB004580, 2014b.

Nehrkorn, T., Eluszkiewicz, J., Wofsy, S. C., Lin, J. C., Gerbig, C., Longo, M., and Freitas, S.: Coupled Weather Research and Forecasting-Stochastic Time-Inverted Lagrangian Transport (WRF-STILT) model, Meteorol. Atmos. Phys., 107, 51-64, doi:10.1007/s00703-010-0068-x, 2010.

Pan, L. L., Bowman, K. P., Atlas, E. L., Wofsy, S. C., Zhang, F., Bresch, J. F., Ridley, B. A., Pittman, J. V., Homeyer, C. R., Romashkin, P., and Cooper, W. A.: The StratosphereTroposphere Analyses of Regional Transport 2008 Experiment, B. Am. Meteorol. Soc., 91, 327-342, doi:10.1175/2009BAMS2865.1, 2010.

Pickett-Heaps, C. A., Jacob, D. J., Wecht, K. J., Kort, E. A., Wofsy, S. C., Diskin, G. S., Worthy, D. E. J., Kaplan, J. O., Bey, I., and Drevet, J.: Magnitude and seasonality of wetland methane emissions from the Hudson Bay Lowlands (Canada), Atmos. Chem. Phys., 11, 3773-3779, doi:10.5194/acp-11-3773-2011, 2011.

Shiga, Y. P., Michalak, A. M., Gourdji, S. M., Mueller, K. L., and Yadav, V.: Detecting fossil fuel emissions patterns from subcontinental regions using North American in situ $\mathrm{CO}_{2}$ measurements, Geophys. Res. Lett., 41, 4381-4388, doi:10.1002/2014GL059684, 2014.

Turner, A. J., Jacob, D. J., Wecht, K. J., Maasakkers, J. D., Lundgren, E., Andrews, A. E., Biraud, S. C., Boesch, H., Bowman, K. W., Deutscher, N. M., Dubey, M. K., Griffith, D. 
W. T., Hase, F., Kuze, A., Notholt, J., Ohyama, H., Parker, R., Payne, V. H., Sussmann, R., Sweeney, C., Velazco, V. A., Warneke, T., Wennberg, P. O., and Wunch, D.: Estimating global and North American methane emissions with high spatial resolution using GOSAT satellite data, Atmos. Chem. Phys., 15, 7049-7069, doi:10.5194/acp-15-7049-2015, 2015.

Wania, R., Melton, J. R., Hodson, E. L., Poulter, B., Ringeval, B., Spahni, R., Bohn, T., Avis, C. A., Chen, G., Eliseev, A. V., Hopcroft, P. O., Riley, W. J., Subin, Z. M., Tian, H., van Bodegom, P. M., Kleinen, T., Yu, Z. C., Singarayer, J. S., Zürcher, S., Lettenmaier, D. P., Beerling, D. J., Denisov, S. N., Prigent, C., Papa, F., and Kaplan, J. O.: Present state of global wetland extent and wetland methane modelling: methodology of a model inter-comparison project (WETCHIMP), Geoscientific Model Development, 6, 617-641, doi: 10.5194/gmd-6-617-2013, 2013.

Wecht, K. J., Jacob, D. J., Frankenberg, C., Jiang, Z., and Blake, D. R.: Mapping of North American methane emissions with high spatial resolution by inversion of SCIAMACHY satellite data, J. Geophys. Res.-Atmos., 119, 7741-7756, doi:10.1002/2014JD021551, 2014. 